\title{
Methodological approaches for the state as well as a prospect analysis of the development of city water supply systems
}

\author{
Anatoly Hurynovich ${ }^{1, *}$, Vitali Baitsou ${ }^{2}$ \\ ${ }^{1}$ Belostok Technical University, Engineering Systems in Environment Protection Department, 15- \\ 351, Vejska str., 45, Bialystok, Poland \\ ${ }^{2}$ LLC «GeoCentreGroup», Instrumentalny lane 5 office 31, 220012, Minsk, Belarus
}

\begin{abstract}
The need to develop methodological approaches for an analysis of the state, as well as the prospects for the development, of water supply systems in small towns is due to a comprehensive assessment of problems and the need to solve problems related to the optimization of current costs and investments. The main stages of research are considered, the result of which is the development of measures to optimize and intensify water supply systems. Methodological approaches are proposed that make it possible to obtain mathematical models adequate to the existing hydraulics of the system to the maximum possible extent: the water supply network-pumping stations-water wells. The studies are based on the use of modern information technologies for the collection of data and their processing, as well as the development of technical solutions.
\end{abstract}

\section{Introduction}

The need to develop methodological approaches of the state and a prospects analysis of the water supply systems in small towns is conditioned by the need to accomplish, at the stage of its feasibility study (FS), activities optimizing investment and operating costs [1,2]. An obligatory condition for the FS development has to be a mathematical modeling of the hydraulics of the water supply system. The hydraulic potentials' working knowledge of the town water supply line is extremely important while, both grounding linking up new water consumers to the acting water supply line, and constructing new lines and water intakes. The water supply system mathematical model presence allows making sound technical and economical decisions of its development prospective directions, taking into account modern innovative technologies that minimize capital and operating costs.

The quality of the water supply system mathematical modeling results is significantly influenced by the following factors:

- reliability of data on the water supply facilities topological configuration;

- geoinformation system (GIS) availability;

- technical condition of the elements of water supply facilities;

\footnotetext{
* Corresponding author: a.gurinowicz@pb.edu.pl
} 
- monitoring system availability and the completeness of the technological parameters of elements operating in water supply facilities;

- availability of integrated billing systems with geospatial information about water consumers, serving to the initial data in an automatic mode arrangement;

- hour-and-second costs archival values databases availability;

- availability of data for hydraulic parameters systematic measurements of both at characteristic water supply line segment, and groundwater well.

Stages of proposed methodological approaches of the state and a prospects analysis of the development of water supply systems: information collection, study and processing; full-scale examinations; the processing and analysis of survey materials; the development of optimization and intensification measures.

\section{Information Gathering, Study and Processing}

The mathematical modeling of the schematic arrangement of hydraulics calculation for a water supply system is reasonably conducted within a GIS enterprise creation framework, which originally was intended for the spatial data and related information on objects represented in the GIS collection, storage, analysis and visualization. Information from maps and terrain plans is easier and more visible for understanding, analyzing and interpreting than text and digital information, tables, graphs and drawings.

An object-oriented approach is used to build a spatial model. Each GIS object is represented in the classifier and is described by a set of its properties - physical and operational characteristics, as well as display methods in the system. In addition, the relationships between objects are described. Combinations of these elements form spatial models of objects. A classifier allows the systematization of objects and its spatial relationships accurately and uniquely.

Today`s GIS is an integrated environment that allows uniting and systematizing various information flows from many departments and services.

\section{Entering Data on Consumer Expenses and Obtaining Nodal Costs}

In recent years, software vendors Bentley (WaterGEMS, WaterCAD), DHI (Mike Uraban), Polyterm (ZuluHydro) and etc. offer dynamic modeling for hydraulic calculations, which allows studying the line hydraulics online, hourly, daily, weekly, yearly [3].

In dynamic modeling, the average hourly water consumption per day of average daily water consumption is introduced as a calculated node selection and a schedule of hourly, daily, annual disequilibrium is assigned to every consumer (Fig.1).
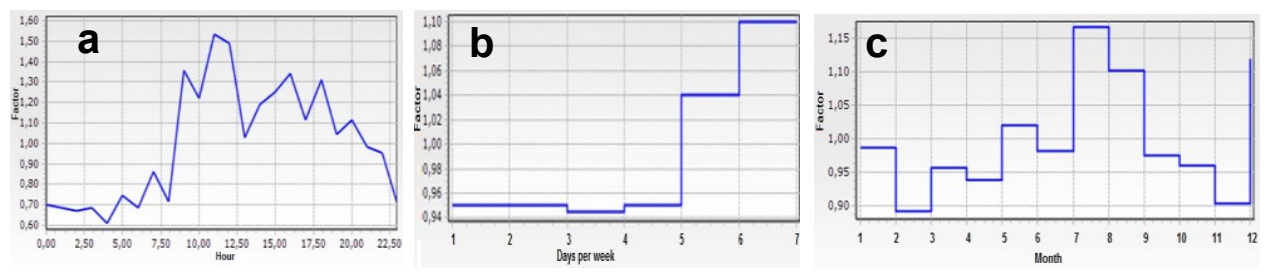

Fig. 1. Graphs of uneven water consumption: a-hour, b-day (days per week), c -month.

The simplest and most qualitative method for setting the average daily flow to the node of the calculation schematic is one water consumer - one node (Fig. 2). 


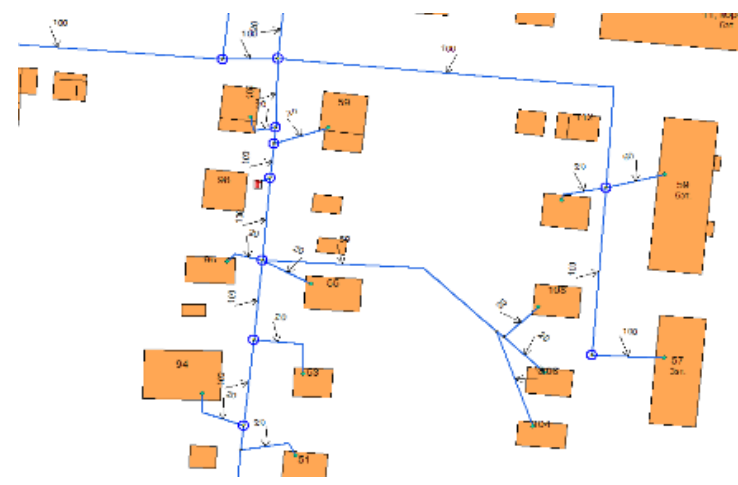

Fig. 2. Water supply line schematic with pointing each water.

An ideal solution that allows automating the information input on the node selection in the calculation schematic is the geocoded importation of water consumption data from the billing system [4].

In the absence of automated systems, the average hourly water consumption is carried out according to the data of the water consumer department of the enterprise. In this case, the monthly consumption is taken as a basis, divided by the number of hours in a month and divided by the monthly non-uniformity factor. For concentrated consumers, such as plants, factories, etc. the average hourly flow is obtained by dividing the monthly consumption by the number of hours in a month and dividing by the monthly coefficient of irregularity.

The hourly irregularity of water consumption by an enterprise has to be determined by one of the following methods:

1 On a questionnaire, which will reflect the water consumption schedule or the enterprise operation mode

2 A more accurate way - through instrumental studies (stationary and portable flowmeters)

Having information about the town's water consumers, one can obtain information about the estimated water consumption of the town $Q_{t}^{g}$ a at any time $t$

$Q_{t}^{g}=\sum_{i=1}^{i=n} Q_{\text {av.hour }}^{\text {cold } n} \cdot K_{h, \text { hour }}^{\text {cold } n} \cdot K_{d, \text { day }}^{\text {cold } n} \cdot K_{m, \text { month }}^{\text {cold } n}+\sum_{i=1}^{i=n} Q_{\text {av.hour }}^{\text {hot } n} \cdot K_{h, \text { hour }}^{\text {hot } n} \cdot$

$K_{d, \text { day }}^{\text {hot }, n} \cdot K_{m, \text { month }}^{\text {hot } n}+\sum_{i=1}^{i=b} Q_{\text {av.hour }}^{\text {concentr.,b }} \cdot K_{h, \text { hour }}^{\text {concentr.,b }} \cdot K_{d, \text { day }}^{\text {concentr..,b }} \cdot K_{m, \text { month }}^{\text {concent., }}$,

where $Q_{\text {av.hour }}^{\text {cold } n}, Q_{a v \text {.hour }}^{\text {hot } n}, Q_{a v \text {.hour }}^{\text {concentr, }}$ - average hourly flow of cold and hot water of water consumers with a degree of improvements $\mathrm{n}$ and concentrated water consumers (enterprises, administrative buildings, etc.); $K_{h \text {,hour }}^{\text {cold, } n}, K_{h \text {,hour }}^{\text {hot } n}, K_{d, \text { weekdays. }}^{\text {concentr, }}-$ coefficient of hourly irregularity of cold and hot water of water consumers with a degree of improvement $\mathrm{n}$ and concentrated water consumers; $K_{d, \text { day }}^{\text {cold } n}, K_{d, \text { day }}^{\text {hot } n}, K_{d, \text { day. }}^{\text {concentr. } b}$ - coefficient of daily irregularity of cold water on the days of the week of water consumers with the degree of improvement $n$ and concentrated water consumers; $K_{m \text {,month }}^{\text {cold, } n}, K_{m \text {,month }}^{\text {hot, } n}, K_{m \text {,month }}^{\text {concentr, }}-$ coefficient of monthly irregularity of cold and hot water of water consumers with a degree of improvement $\mathrm{n}$ and concentrated water consumers. 


\section{Skeletization of the mathematical model of water supply hydraulics}

When constructing detailed water supply schematics, the nodes number makes the schematic difficult to read and therefore difficult to understand

To simplify the initial data analysis and the calculation results, a simplification (skeletization of mathematical model of water supply hydraulics) of the mathematical model of water supply line hydraulics is often applied [5]. WaterGEMS software allows performing automatic skeletization of the mathematical model of water supply hydraulics-simplification of the calculation schematic according to the user-defined algorithm with preservation of its hydraulic integrity.

When simplifying the work according to the mathematical model skeletization of hydraulics of the Rogachev town water supply line, the number of computed areas was reduced from 6778 to 398, and nodes - from 6054 to 269 (Fig. 3).

Based on the results of simplification, the question arises: how to distribute node synthetic flow so that in the end result it does not affect the hydraulic modeling quality?

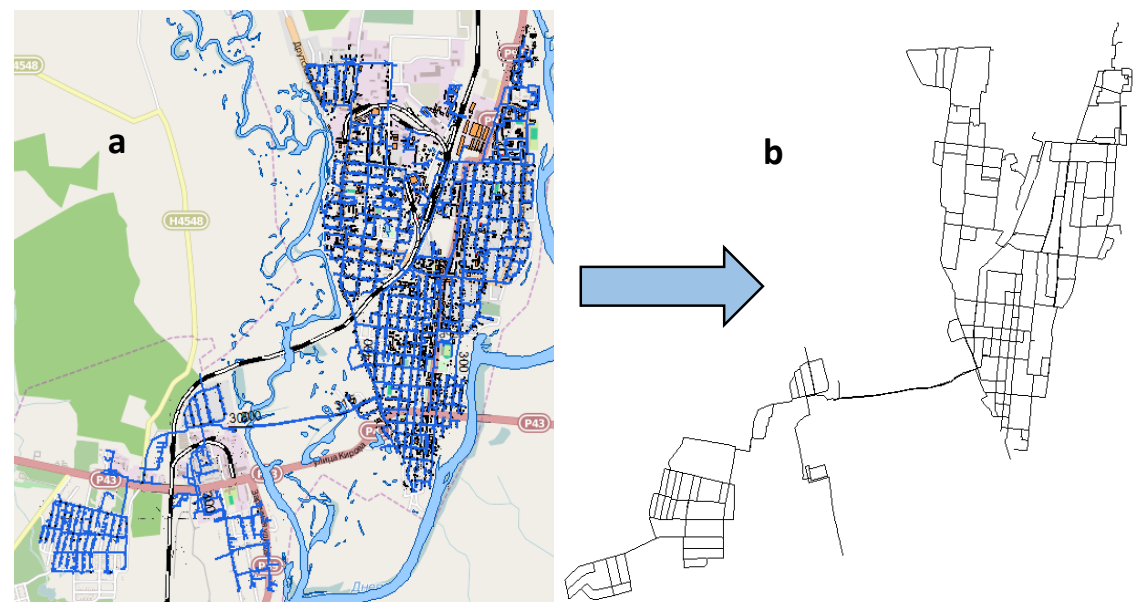

Fig. 3. Mathematical modeling of a water supply system schematic before skeletization - a and after skeletization $-\mathrm{b}$.

There are various methods and technological approaches to solve this problem [6]. WaterGEMS V8i software allows assigning the calculated water consumption in one of the following ways.

1. Combined and aggregate invoices from the billing system. This method allows linking data on water consumption from the billing system to the nodes of the calculation schematic.

The billing system allows calculating the cost of water and sewerage services for each customer and stores information about all tariffs and other cost characteristics that are used by services with consumers for invoicing.

2. Binding to the nearest calculation schematic node.

This method allows assigning the estimated costs of water consumers to the calculated node of the schematic. This method uses the capabilities of spatial GIS analysis to assign geocoded data to the nearest node or pipe (Fig. 4). 


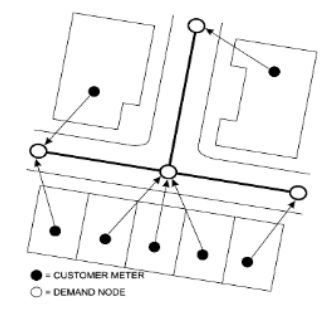

Fig. 4. Binding data to the nearest node.

Ideally, the anchor point of the object in the GIS must coincide with the location of the water consumer's water meter.

3. Binding to the nearest pipe.

The method of binding to the nearest pipe assigns checkout system of the load circuit of the water consumers to the nearest pipe, and then distributes the loads using custom criteria.

This method uses the capabilities of spatial GIS analysis to assign geocoded data to the nearest pipe. Next, the system has to be proposed for the following strategy and methods for distributing nodal selections.

1. Weighted distribution.

This method allows distributing part of the total load assigned to the pipe, based on the distance between the water consumers and the nodes at the ends of the pipe. The closer the water consumer is to the end of the pipe (node), the more load will be assigned to it.

2. Equal distribution.

This method assigns an equal part of the total load assigned to the adjacent pipe to each of the final nodes of the calculation section.

3. The nearest node

This method assigns the total load assigned to the end node of the pipe, which is closest to the water consumer.

4. The farthest node

This method assigns the total load assigned to the end node of the pipe, which is closest to the water consumer.

\section{Full-Scale Examinations}

In order to find out how the town water supply system works and make necessary adjustments to its operation in the future, it is necessary to make a piezometric survey of the water supply line. Such a survey can be obtained with the use of stationary and temporary pressure and flow control points. When performing a piezometric survey of a water supply line using autonomous pressure recorders (time pressure control points), athe sequence of work should be performed: selection of line points for measuring pressures; supplying equipment to selected locations, taking into account the installation of autonomous pressure registers; geodetic survey of each point; conducting measurements; processing of manometric survey materials; repeated piezometric survey; and systematization of piezometric survey materials. When choosing the measurement points, it is advisable to place them on the main lines, along the water flow from the pumping stations to the most remote consumers, and in the case of power supply of the line ,by several pumping stations - to the expected points of the stream meeting.

Checkpoints are planned: in places on the branches from pipe mains; in places of higher geodetic marks; near high buildings; in places where there are insufficient free heads. The diagram of the water pipe (Fig.5) shows the location of the measuring points. 
Pressure measurements are carried out simultaneously, if possible, at all the most critical points. In a case where there are not enough devices for this purpose, the system is divided into separate independent zones.

If there are several pumping stations supplying water to different zones or sections of the line, the survey shall be carried out by the zone or area served by the pumping station.

When a number of pumping stations operate in one zone, the survey should be carried out in the direction of counterflow in the pipe mains, which makes it possible to determine the impact zone of each pumping station.

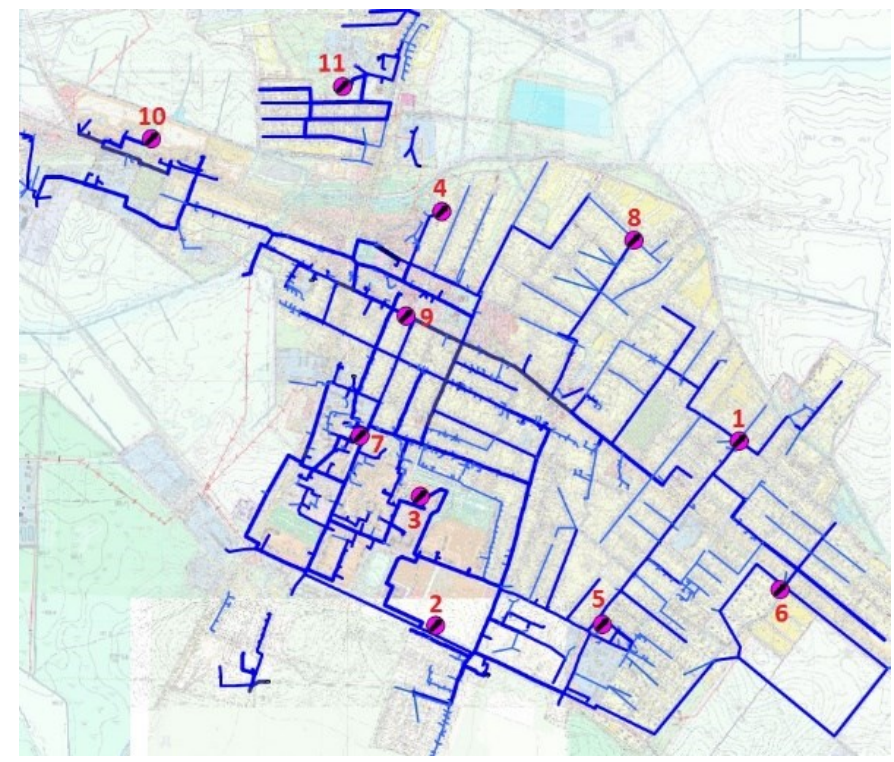

Fig. 5. The water supply line schematic with the location of the installation of autonomous pressure recorders (1-11).

\section{Processing and Analysis of Survey Materials}

For the practical application of mathematical modeling of the hydraulics in a water supply system, it is necessary that the calculated values of pressure at the nodes and pipeline costs have the minimum permissible deviations from the actual ones.

In the process of model calibration, the capabilities of the mathematical modeling system and the maximum allowable amount of actual data on costs and pressures from the piezometric survey data, current data from the monitoring system of technological parameters are used in the actual operation of the network. Software products such as Bentley® WaterGEMS offer automatic calibration of the mathematical model. The advantage of the Bentley ${ }^{\circledR}$ WaterGEMS software is the use of a genetic algorithm for calibrating a mathematical model, in which the coefficients of equivalent roughness of pipelines, nodal consumption, are subject to calibration.

Genetic algorithms are based on the principles of natural selection. So in the studies of the water supply line in Cherven, the calibration of the mathematical model was based on 722 fullscale measurements of flow and pressure. The calibration conditions were set: the maximum number of samples $5 \mathrm{mln}$, the left solutions -3 , the generation without improvement -200 , the error of correspondence -0.001 , the maximum number of evolution -6 , the number of generations for evolution -150 , the size of the population -50 , the possibility of dividing -1 , $7 \%$, the possibility of crossing $-90 \%$, the possibility of mutations $-1.0 \%$. At the 3564216 step, 
generation of the results of the calibrated models reached the state at which the genetic algorithm reached a maximum similarity to the results of field measurements. The root-mean-square error of the best solution is 16,565 .

The visualization of the state of the capacity of the water supply line is shown in Fig.6, where it is possible to see the problematic sections of pipelines.

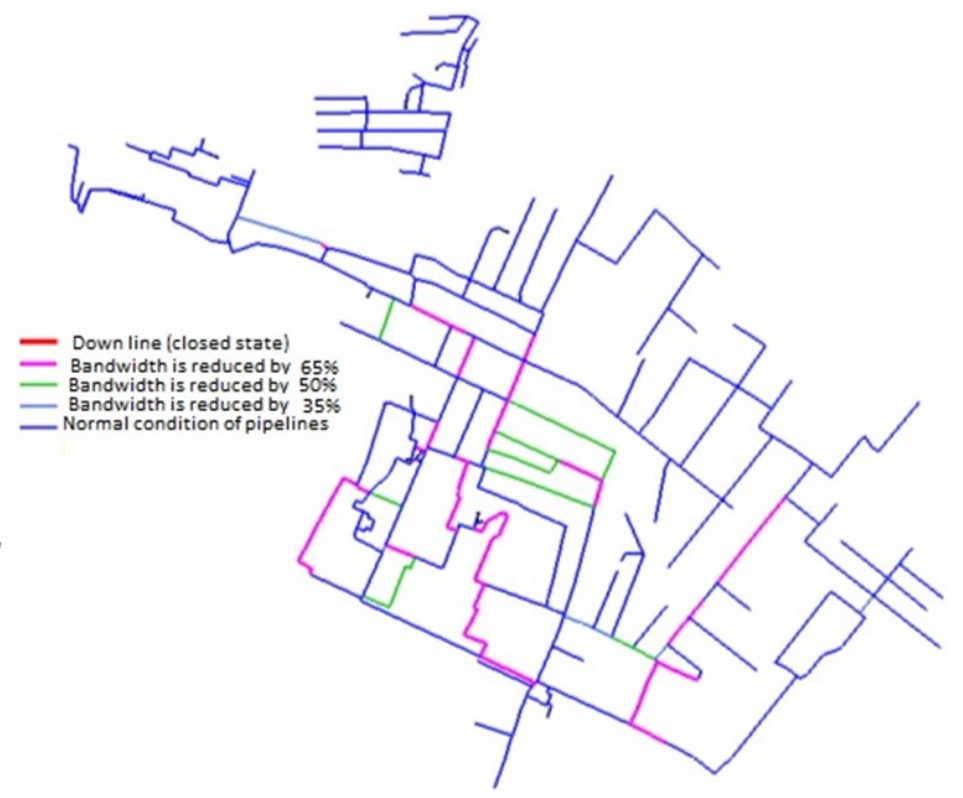

Fig. 6. Water supply line schematic with roughness coefficients with state estimation of carrying capacity.

\section{Optimization and Intensification Measures Development}

The water supply line hydraulics mathematical model, which successfully passed calibration, becomes the main tool for optimization and intensification measures development. It allows: choosing the optimal mode of water supply in order to reduce costs; optimizing zoning and choosing pumping equipment; evaluating the efficiency of renovation of acting water supply systems that require the re-installation or replacement; simulating pipeline shutdowns in order to assess and minimize the definition of thereliability of the water supply line.

When the water supply system with well water intakes is explored, new approaches of water supply line hydraulics mathematical modeling are included in the joint analysis of the operation of well water intakes ( $\left(1^{\text {st }}\right.$ upheave), prefabricated water intake pipes, clean water tanks, pumping stations of the $2^{\text {nd }}$ upheave and the town water distribution line. This approach allows solving the problems associated with minimizing the total unit costs of energy consumption at all stages from the extraction of water from underground sources to the supply of water to end consumers.

When solving tasks to minimize the energy costs of the water supply facilities, an assessment should be made of the effect of regulatory tanks on the costs associated with supplying water to consumers.

The optimal option for technical solutions and related investments will be with a minimum life cycle cost (LCC - Life Cycle Cost), including the total cost of construction (reconstruction) and operation during the estimated service life [7]. 


\section{Conclusions}

The proposed methodological approaches, based on the application of modern information technologies for the collection of initial data and their processing, make it possible to obtain mathematical models adequate to the acting hydraulics of the system to a maximum extent: water wells - pumping stations - a water supply line, and develop optimal technical solutions for the future development of town water supply systems.

\section{References}

1. Hurinovich A. D. Drinking water supply systems with deep wells: planning, designing, constructing and operating. ( Tekhnoprint Publ, Belarus, 2004)

2. Batchabani E., Fuamba M. Optimal tank design in water distribution networks: review of literature and perspectives. J. Water Resour. Plan. Manag. 140, 136-145 (2014)

3. Orlov V.A., Averkeev I.A. Proceedings of Moscow State University of Civil Engineering, 4, $237-243$ (2013)

4. Integrated automated management system for housing and public utilities. (LLC "Billing Online", 2013)

5. F. Javier Martínez-Solanoa, Pedro L. Iglesias-Reya, Daniel Mora-Meliáb and Vicente S. Fuertes-Miquela. XVIII International Conference on Water Distribution Systems Analysis, WDSA 2014. Procedia Engineering, 186, 286 - 293, (2016)

6. H. Motiee, E. McBean \& A. Motiei Urban Water J., 4, 43-52, (2007)

7. Syczewa E., Hurynovich A. . J. European Association of Environmental and Resource Economists, Polish Division, 6, 67-76 (2013) 